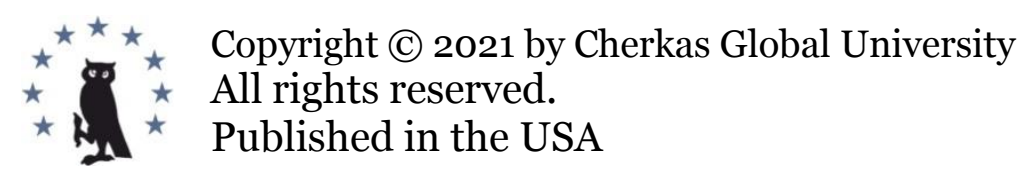

European Journal of Contemporary Education

E-ISSN 2305-6746

2021. 10(4): 981-986

DOI: 10.13187/ejced.2021.4.981

https://ejce.cherkasgu.press

IMPORTANT NOTICE! Any copying, reproduction, distribution, republication (in whole or in part), or otherwise commercial use of this work in violation of the author(s) rights will be prosecuted in accordance with international law. The use of hyperlinks to the work will not be considered copyright infringement.

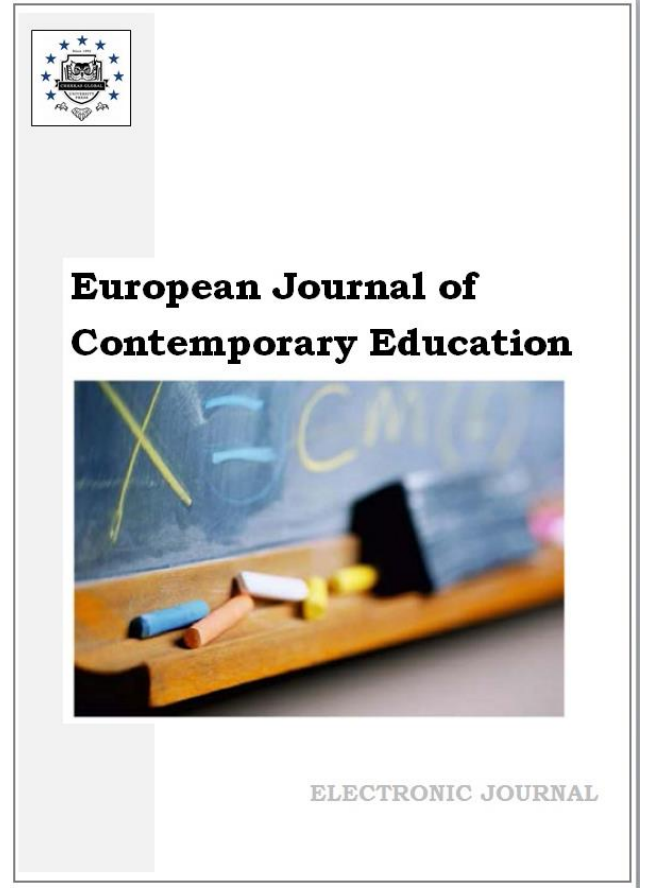

\title{
Exploring Cyberbullying and its Implications on Psychosocial Health of Students in Accra, Ghana: A Thematic Analysis
}

Yvonne Otubea Otchere a, Erika Primo a, Jacob Owusu Sarfo b , c, d , *

${ }^{a}$ Lancaster University, Accra, Ghana

b University of Cape Coast, Cape Coast, Ghana

${ }^{\mathrm{c}}$ Cherkas Global University, Washington, DC, USA

d Volgograd State University, Volgograd, Russian Federation

\begin{abstract}
Globally, there is a surge in the cases of cyberbullying. Our study explored the concept of cyberbullying and its effects on the psychosocial health of students in Accra, Ghana. We collected semi-structured interviews from six students (three females and three males) who have past lived cyberbullying experiences. From our thematic analysis, six major themes emerged: (1) forms of cyberbullying, (2) reasons for engaging in the act of bullying, (3) effects of cyberbullying, (4) strategies for coping with cyberbullying, (5) perpetrators and victims of cyberbullying, and (6) prevention of cyberbullying. The results also showed that the most common cyberbullying types were in the forms of posting nudes, revenge porn, and rude comments. Perpetrators of cyberbullying did so for fun, revenge, insecurities, jealousy, power-play, and transfer of emotions. Also, victims of cyberbullying often experience mental health problems like depression, suicidal thoughts, anxiety, paranoia and avoidance. We also observed that the victims use emotional support and rational (problem-solving) coping strategies, while bullies adopt revenge coping. Regarding participants' perception of cyberbullying prevention, all participants agreed that cyberbullying could be reduced or prevented by creating awareness and ensuring social media responsibility. Our study has implications for policy, psychological interventions, and further research in Ghana.
\end{abstract}

Keywords: cyberbullying, Ghana, psychosocial health, students, victims.

\footnotetext{
* Corresponding author

E-mail address: jacob.sarfo@ucc.edu.gh (J.O. Sarfo)
} 


\section{Introduction}

Our lives are surrounded by our mobile phones, laptops, and other electronic devices in this modern era. The internet has helped many stay connected through social media and gives people more exhaustive information, games, etc. (Abaido, 2020). With advancements in technology and the internet, cyberbullying has become a remarkable phenomenon practised by children, adolescents and young adults. Chisholm and Day (2013) defined cyberbullying as "the intentional and repeated harm inflicted through the use of computers, cell phones, or other electronic devices" (p. 36). Unfortunately, with technological advancement, students are exposed to technology very early, causing them to deal with cyberbullying very early on WhatsApp, Instagram, Snapchat, Facebook, etc. (Nixon, 2014). According to Nixon (2014), young people expect to be bullied either traditionally or through cyberspace, showing that bullying is the new normal. Unfortunately, Sam et al. (2017) noted cyberbullying is becoming a growing concern among Ghanaian students as everyday behaviour.

Notwithstanding the increasing volume of research on cyberbullying (Abaido, 2020), very few studies have been done regarding students' lived experiences in Africa, specifically Ghana as a country. Comparitech.com (2018) suggested that cyberbullying in Africa is on ascendency with the sparse research done. Similarly, Agbeko and Kwaa-Aidoo (2018) indicated that about six per cent of their total study participants from Southern Ghana had experienced cyberbullying. Based on the findings of Agbeko and Kwaa-Aidoo (2018) and Sam et al. (2017), it is essential to conduct this study to know the lived cyberbullying experiences of students in Accra (Capital City of Ghana) and its psychosocial effects. More importantly, Ghana may not be able to achieve Sustainable Development Goals 3 (good health and wellbeing) without sufficient empirical evidence to understand the problem of cyberbullying.

\section{Materials and methods \\ Design}

We used a cross-sectional correlational design to explore students' lived experiences in Ghana. Following ethical clearance by Lancaster University Ethics Committee, we purposively sampled six (three females and three males) university students who have experienced cyberbullying, either as victims or perpetrators. Their ages ranged between 18 and 23 years, and they had experienced cyberbullying at least once.

After obtaining informed consent from the participants, we conducted a semi-structured interview until saturation. We adopted Guba and Lincoln's (1989) principles to meet the trustworthiness criteria during the study process. In order for participants' identity to be anonymous, each participant was given a pseudonym by the researchers. Participants were allowed to ask any question and were also reminded that participation was entirely voluntary, and they could withdraw at any point in time. Also, participants were informed that there would be free and accessible therapeutic services at the Lancaster Counselling Center if they experienced any distress during the interviewing process.

The interviews lasted averagely for 20 minutes via both face-to-face (four interviews) and telephone (two interviews). At data saturation, interviews were transcribed and analysed thematically with the help of NVivo software.

\section{Results and Discussion}

This research consisted of an interview about cyberbullying, specifically the participants' experience with cyberbullying. We conducted thematic analysis for the interview data after reaching data saturation.

From our analysis, we identified six major themes: (1) forms of cyberbullying, (2) reasons for engaging in the act of bullying, (3) effects of cyberbullying, (4) strategies for coping with cyberbullying, (5) perpetrators and victims of cyberbullying, and (6) prevention of cyberbullying.

Theme 1: Forms of cyberbullying

Participants suffered from various forms of cyberbullying. Participants reported bullies' abusive behaviours such as posting rude messages, threats, nude photos of victims, and creating fake profiles to insult or send false information about victims. For example, a participant who has been a victim described his cyberbullying experience like this: "a girl created a Twitter account, only to say rude things and start fake rumours about me as well as fake rumours about my boyfriend at the moment" (Daniele). Another victim, Kim, who was bullied twice, reported: 
"the first time was just two girls who left rude comments on a picture I posted while the second time, I had my nude photo leaked by a fake Instagram account”. Aside from the victims, participants who were bullies also confirmed the use of rude messages against their opponents. For example, Josh said he abused others online by "texting people in a really rude way."

Additionally, cyberbullying took the form of posting victims nude pictures. Nick described a naked photo of a female friend on Snapchat by an anonymous account. He stated that: "an anonymous account posted a nude picture of a female friend and the picture publicly went viral on Snapchat recently". Rose reported another example of cyberbullying that involved nude photos. She said, "he threatened me that he would make my life miserable by posting online the nude pictures I had sent to him while we were dating." Results suggest that nude photo leaks and rude posts or mean comments were the most popular types of cyberbullying among students in Ghana.

Congruent to this finding, Agbeko and Kwaa-Aidoo (2018) noted that fraping (where a bully uses someone's account to post inappropriate content) and harassment were the most typical forms of cyberbullying among their sample from Southern Ghana. In some international studies, Slonje and Smith (2008) identified leaked sex tapes and nude pictures, blackmail, threats, calling of names, revenge porn, and creating fake accounts to spread rumours as some commonest forms of cyberbullying.

\section{Theme 2: Reasons for engaging in the act of bullying}

The second theme indicated that most of the perpetrators of cyberbullying did so for the following reasons; fun, revenge, insecurities, jealousy, power-play, and transfer of emotions. A participant described the reason for bullying as "jealousy, envy, but others do it just for the fun of it." A male bully reported that he engaged in cyberbullying as revenge. An extract from his interview is as follows: "... he physically beat me up... so I decided to give him a taste of his own medicine. As he was a bully, I got my revenge on him by texting him with rude messages".

An example of bullying for fun was observed from the words of Nick. He stated that "I did that to tease..." Participants like Rose said, "people are not happy about certain things about themselves, so they bully others to cover-up". Thus, we observed that some bullied others due to their perceived insecurities. Also, Nick described power as a motive by saying that "some abuse people online to show their power over the so-called weak". Daniele and Rose told their cyberbullying experience are a clear example of jealousy. According to Daniele, "my boyfriend's exgirlfriend created a Twitter account, only to say rude things and start fake rumours." Also, Rose stated that her jealous ex-boyfriend threatened her after their relationship got broken. An extract from her states: "my ex-boyfriend at the time decided that he would make my life miserable by threatening to send my nude pictures".

Additionally, some participants described the transfer of emotions as part of the motive of bullying. Daniele stated, "others engage in cyberbullying because they are in pain and would like others to feel their pain as well". Josh, for example, is a clear example. He noted that "... people were attacking me online. So I decided to give them a taste of their own medicine." Consequently, being hurt by a person made these participants want to make their victims feel the same pain. This theme is supported by Raskausas and Stolts (2007), who found that adolescents bully to have fun, revenge, acquire power and state of their mood (p. 570).

Theme 3: Consequences of cyberbullying

We asked participants to share from their experiences the consequences of cyberbullying. The effects were depression, avoidance, paranoia, suicide, embarrassment, shame, hurt, and blame. For example, Daniele expressed: "I was scared all these people out there, including those who don't even know me, were reading these false things about me. I felt very sad, angry got into a deep depression". Kim had a more substantial effect due to the level of cyberbullying (leaked nude photos). She said: "I felt embarrassed, I got depressed, ashamed, avoided people... I even became so paranoid". Rose suffered a similar effect, as she reported: "I was very depressed, I used to cry more than 20 times a day... I couldn't eat nor sleep".

Participants also described that victims might suffer from other effects like the example given by Nick. According to him, "victims can suffer from depression, anxiety, suicide". He also described the impact of cyberbullying on a girl whose naked photo was leaked on social media. He said: "...the girl then started to live-stream her suicide attempt. She explained she wanted to take her life because of the depression from online abuses after the leak". Rose also said that 
victims could suffer from “... depression, suicide, and psychosis”. From the perspective of a bully, the results showed that they knew that cyberbullying affected their victims negatively. Josh recalled that: "he deserved everything he was experiencing... from what I saw from his behaviours, he started getting sad, and everyone could see a change in his behaviour". Thunderbird, also a bully, said that "those who experience such online bullying became sad, hurt, and suicidal."

According to evidence, victims of cyberbullying tend to suffer from depression, anxiety, low self-esteem, emotional distress, mental distress and poor academic performance (Abaido, 2020; Beran, Li, 2005; Nixon, 2014; Sam et al., 2017). Furthermore, research suggests that the psychological effects of cyberbullying are not restricted to its victim only. According to Carney (2000), perpetrators also have adverse psychological effects such as suicidal thoughts, depression, and conduct disorder such as substance abuse.

Theme 4: Strategies for coping with cyberbullying

Coping in this finding refers to how the victims dealt with their bullying experience. The most frequent responses were emotional, rational, and revenge. From the analysis, victims tend to use emotional support and rational (problem-solving) coping strategies, while bullies adopt revenge coping.

An emotional coping strategy was suggested and used by most participants. For example, when asked how she could cope with the situation, Daniele replied, "I sought emotional support in my friends and boyfriend at the time." Kim, who had suffered cyberbullying twice, reported that: "I opened up to my mum about it to be supported emotionally." According to Nick, he could cope by "talking to my close friend about the situation and how it was making me feel." Rose, whose bully controlled her life for some time, responded that "I spoke to someone... she really allowed me to cry on her, and she kept supporting me the whole time".

Other participants also engaged in revenge coping. Thunderbird shared that he said mean words to people who bullied him. An extract from his interview read: "... anytime they said mean words to me, I also replied by saying mean words as well, insulting, teasing”. Josh explained that his reason for bullying was "to get revenge." This perception existed since he saw his victim also bullied him online as well. Josh did not think in emotional support being a victim of traditional bullying. When asked if he spoke to anyone about it, he said, "no, I was feeling embarrassed".

Participants also reported using a rational coping approach which was generally problemsolving. According to Rose, she took a rational approach to stop the bullying. An extract stated: “... well, I paid someone to remove the pictures from social media for me." Nick, Daniele, and Kim shared a similar view. Nick said, "such a behaviour should be reported for the perpetrators to be punished."

The theme also showed that emotional and rational/problem coping approaches are preferred when dealing with cyberbullying. This finding is from our present study is different from that of Abaido (2020), Dubow and Rubinlicht (2011), and Varjas et al. (2009), who argue that victims tend to use less optimal coping strategies such as avoidance. Raskauskas and Huynh (2015) also observed that adolescents use avoidant coping strategy rather than problem-solving from their systematic review.

Theme 5: Perpetrators and Victims of cyberbullying

We asked participants which gender was bullied (victim) or bullied (perpetrators) the most. Daniele responded: "both boys and girls bully equally." Nick and Thunderbird also agreed on the assertion that both males and females engaged in cyberbullying. However, Josh and Rose reported that males bully more while Kim believed that females indeed bully more.

Concerning victims of cyberbullying, most participants believed that females were most vulnerable. Daniele responded, "girls get bullied the most across all ages". Kim, Nick and Rose seemed to agree to this assertion. Nick based his argument on the fact that "girls get bullied the most especially with this revenge porn". However, Josh expressed that "both boys and girls experienced cyberbullying as victims equally." Thunderbird seemed to disagree with both assertions as he replied, "boys get bullied the most."

From our analysis, participants tend to see victims as sensitive, easy to break, weak and emotional. As Daniele described, "... girls are more sensitive... girls are also more worried about their image, appearance... making it easy for the bully to know their weakness to target at them". Kim believed that bullies tend to peak on the "scared, alone, different, weak", which caused her to conclude that girls get bullied the most. Also, Thunderbird assumed that victims were "sensitive, more emotional, seen as easy targets." 
Previous results on gender tend to show inconsistent findings with the more considerable extant literature depicting gender equality in cyberbullying (Balakrishnan, 2018). However, our results revealed that girls tend to be bullied more than boys, but both boys and girls bully equally. Similar results based on victimisation can be seen in studies by Navarro (2015) and Devine and Lloyd (2012). From these studies, females were seen as easy targets, sensitive, and worried about their images and reputation. On the contrary, Slonje and Smith (2008) noted that boys tend to bully more than girls. They found that " $36.2 \%$ of victims reported being bullied by one boy, and $36.2 \%$ did not know the gender of who bullied them; only $12.1 \%$ were bullied by one girl” (p. 151).

Theme 6: Prevention of cyberbullying

Regarding participants' perception of cyberbullying prevention, all participants agreed that cyberbullying could be reduced or prevented by creating awareness and ensuring social media responsibility. Kim argued, "social media platforms have an anti-cyberbullying policy. You should find a way to log these things as they are happening; it would prevent a lot of things." Also, Nick stated that: “... creating awareness prevents others from being abused online.” Also, Josh replied by saying: "... educate everybody a bit more about cyberbullying and its consequences especially". Researchers like Slonje et al. (2012) recommend prevention programmes as school curriculum-based activities. They gave an example of the anti-bullying program in Finland that supports victims. Notar et al. (2013) also supported this notion of using a school-based awareness programme.

\section{Conclusion and Recommendation}

Cyberbullying is a growing phenomenon. From our thematic analysis, six major themes emerged: (1) forms of cyberbullying, (2) reasons for engaging in the act of bullying, (3) effects of cyberbullying, (4) strategies for coping with cyberbullying, (5) perpetrators and victims of cyberbullying, and (6) prevention of cyberbullying. Our study showed that both bullies and victims are aware of the effects of cyberbullying. Also, the fact is that participants perceive cyberbullying as something negative. Even though they see it as wrong, bullies still bully others for several reasons. Cyberbullying victims need help from a person who genuinely understands. There should also be institutional policies on cyberbullying in schools and colleges to support victims and discourage perpetrators. Psycho-education and contemporary therapeutic intervention are also essential. Further quantitative studies should be conducted using a large national dataset to explore the prevalence of cyberbullying in Ghana.

\section{Acknowledgements}

We are grateful to the authorities and participants for their support.

\section{Conflict of interest}

We declare that we have no conflict of interest in the conduct of this study or declaration of results.

\section{References}

Abaido, 2020 - Abaido, G.M. (2020). Cyberbullying on social media platforms among university students in the United Arab Emirates. International Journal of Adolescence and Youth. 25(1): 407-420.

Agbeko, Kwaa-Aidoo, 2018 - Agbeko, M., Kwaa-Aidoo, E.K. (2018). An exploration of the cyber bullying phenomenon among teenagers in southern Ghana. African Journal of Applied Research.4(2): 119-129.

Balakrishnan, 2018 - Balakrishnan, V. (2018). Actions, emotional reactions and cyberbullying-From the lens of bullies, victims, bully-victims and bystanders among Malaysian young adults. Telematics and Informatics. 35(5): 1190-1200.

Beran, Li, 2005 - Beran, T., Li, Q. (2005). Cyber-harassment: A study of a new method for an old behavior. Journal of Educational Computing Research. 32(3): 265-277.

Carney, 2000 - Carney, J.V. (2000). Bullied to death: Perceptions of peer abuse and suicidal behaviour during adolescence. School Psychology International. 21(2): 213-223.

Chisholm, Day, 2013 - Chisholm, J., Day, S. (2013). Current trends in cyberbullying. Journal of Social Distress and the Homeless. 22(1): 35-57. 
Comparitech.com, 2018 - Comparitech.com. 2018. Cyberbullying statistics and facts for 20162018. [Electronic resource]. URL: https://www.comparitech.com/internet-providers/cyberbullyingstatistics/

Devine, Lloyd, 2012 - Devine, P., Lloyd, K. (2012). Internet use and psychological well-being among 10-year-old and 11-year-old children. Child Care in Practice. 18(1): 5-22.

Dubow, Rubinlicht, 2011 - Dubow, E.F., Rubinlicht, M. (2011). Coping. In B. B. Brown, M. Prinstein and B. Compas (Eds.). Encyclopedia of adolescence. Vol 3. Elsevier.

Guba, Lincoln, 1989 - Guba, E.G., Lincoln, Y.S. (1989). Fourth generation evaluation. Newbury Park, CA: Sage.

Navarro, 2015 - Navarro, R. (2015). Gender issues and cyberbullying in children and adolescents: From gender differences to gender identity measures. Cyberbullying across the globe (pp. 35-61). Springer, Cham.

Nixon, 2014 - Nixon, C. (2014). Current perspectives: The impact of cyberbullying on adolescent health. Adolescent Health, Medicine And Therapeutics. 4(5): 143-158.

Notar et al., 2013 - Notar, C., Padgett, S., Roden, J. (2012). Cyberbullying: Resources for intervention and prevention. Universal Journal of Educational Research. 1(3): 133-145.

Raskauskas, Huynh, 2015 - Raskauskas, J., Huynh, A. (2015). The process of coping with cyberbullying: A systematic review. Aggression and Violent Behavior. 23: 118-125.

Raskauskas, Stoltz, 2007 - Raskauskas, J., Stoltz, A.D. (2007). Involvement in Traditional and Electronic Bullying among Adolescents. Developmental Psychology. 43(3): 564-575.

Sam et al., 2017 - Sam, D.L., Bruce, D., Agyemang, C.B., Amponsah, B., Arkorful, H. (2019). Cyberbullying victimisation among high school and university students in Ghana. Deviant Behavior. 40(11): 1305-1321.

Slonje et al., 2012 - Slonje, R., Smith, P., Frisén, A. (2013). The nature of cyberbullying and strategies for prevention. Computers in Human Behavior. 29(1): 26-32.

Slonje, Smith, 2008 - Slonje, R., Smith, P. (2008). Cyberbullying: Another main type of bullying? Scandinavian Journal of Psychology . 49(2): 147-154.

Varjas et al., 2009 - Varjas, K., Henrich, C., Meyers, J. (2009). Urban Middle School Students' Perceptions of Bullying, Cyberbullying, and School Safety. Journal Of School Violence. 8(2): 159-176. 